\title{
MODIFIED ERECTOR SPINAE PLANE BLOCK FOR THORACIC SURGERIES: PRELIMINARY REPORT OF THE CASES
}

\author{
Sami Kaan COSARCAN ***, Alper Tunga DOGAN*, Ömür ERCELEN** \\ Department of Anesthesiology, American Hospital Istanbul Turkey \\ *DESA-Anesthesiology Specialist, ${ }^{* * \text { Professor, }}{ }^{* * *}$ Anesthesiology Specialist
}

\section{Background}

Erector Spinae Plane (ESP) block is a novel technique inwhich local anesthetic (LA) is injected between the erector spinae muscle and transverse process under ultrasound guidance. It has been used as a postoperative analgesia method in many surgical procedures. The mechanism of action is not clear. There are well-described anatomical gaps in the intertransverse connective tissue that might explain how LA can pass from the ESP into the para-vertebral space. Although it is efficient, in real life there is block failure/lack of efficiency that tells us there might be things to consider about the block. We would like to present our modified technique (ESP-3) aimed more reliable block.

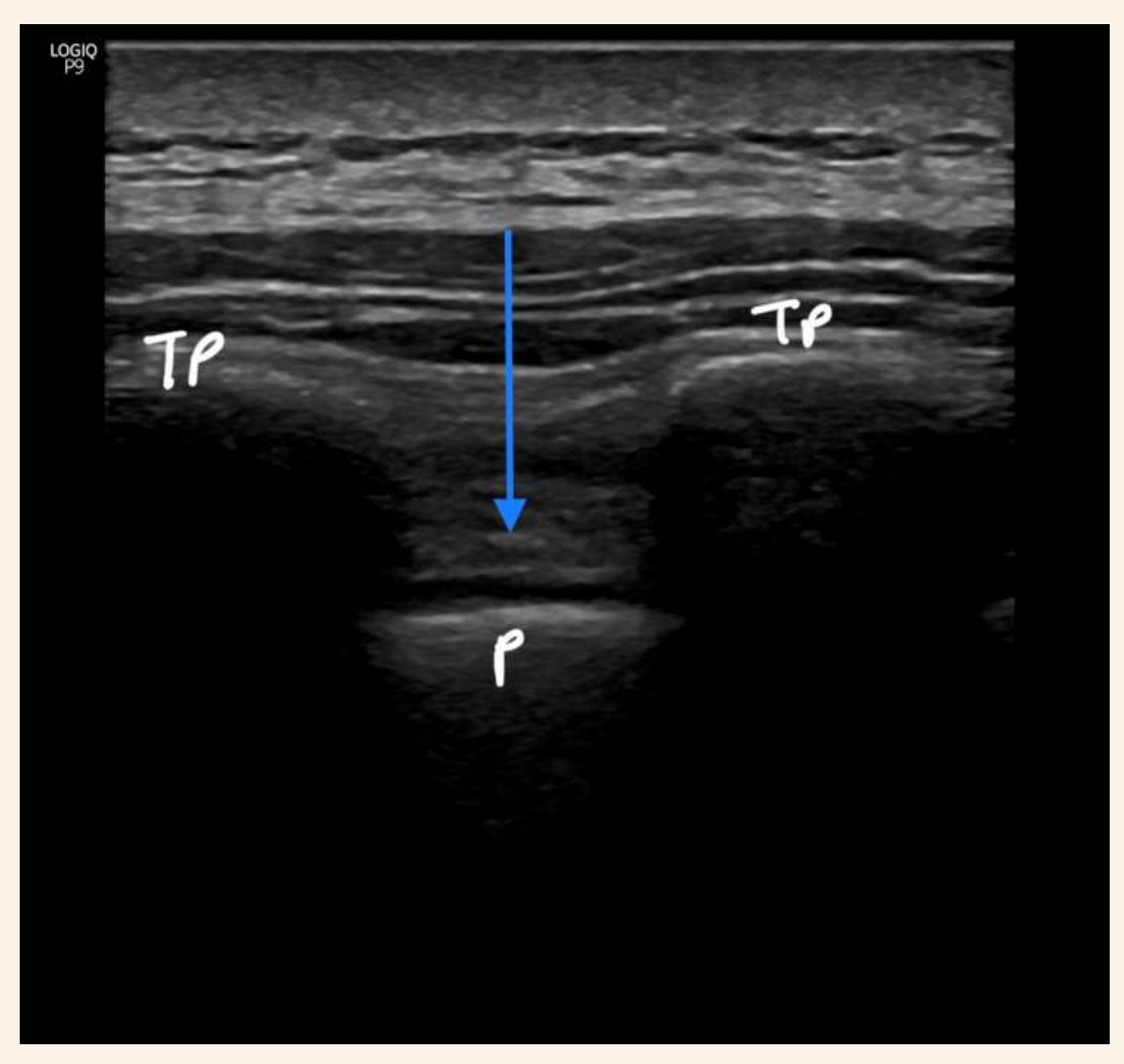

Fig1. Needle point in modified ESPB

\section{Cases}

We perform ESP-3 for 6 patients (1-breast surgery with fleb, 4-thoracoscopic pleurodesis and 1lobectomy). Blocks performed at sitting position. A lineer-ultrasound probe placed longitudinal parasagittal orientation. After transverse process (TP) identified an 22G-echogenic needle (BraunStimuplexUltra360) is inserted in-plane caudal-tocranial approach. The needle tip made contact to TP and $10 \mathrm{ml}$ of Local anesthetic (LA-Bupivacaine) is given to the facial plane. Then the needle moves from the most proximal part of the TP, pass intertransverse ligament and $15 \mathrm{ml}$ of LA is injected just above the superior costotransverse ligament.

\section{Results}

Before the end of the surgeries Non-steroid anti-inflammatory drug and paracetamol was given. None of the patients complained about the pain. No complication was recorded.

\section{Conclusion}

Facial plane blocks are promising. They can be as effective as epidurals. With our modified ESP technique, we hypothesized a more consistent and reliable block can be achieved. 